\title{
Aplikasi Pemetaan Bangunan Berizin Di Kota Manado
}

\author{
Abdul Murzi Pelupessy ${ }^{[1]}$, Yaulie D.Y Rindengan ${ }^{[2]}$, dan Pinrolinvic D. K Manembu ${ }^{[3]}$. \\ murzipelupessy0@gmail.com, rindengan@unsrat.ac.id,pmanembu@unsrat.ac.id
}

\begin{abstract}
Kota Manado sebagai salah satu kota dengan keadaan penduduk yang makin padat dan masi banyaknya penduduk kota manado yang belum memiliki izin mendirikan bangunan, dengan adanya Sistem Informasi Geografis ini. Maka lebih memudahkan dinas terkait mengenai lokasi bangunan yang boleh untuk di dirikanya Izin Mendirikan Bangunan. Oleh karena itu, penulis membuat sistem informasi geografis izin mendirikan bangunan di Kota Manado berbasis web dengan menggunakan HTML (HyperText Markup Language), PHP (Perl HyperText Preprocessor), CSS ( Cascading Style Sheets) dan JavaScript database sistem dan google API untuk pemetaan. Informasi yang disajikan berupa foto bangunan, nama pemilik, lokasi, peruntukan, nomor SKRD (Surat Ketetapan Retribusi Daerah), nomor IMB (Izin Mendirikan Bangunan), tanggal, dan luas. Dengan adanya Sistem Informasi Geografis ini diharapkan dinas terkait dapat lebih mudah mencari lokasi yang dibolehkanya untuk membangun bangunan di Kota Manado.
\end{abstract}

Kata Kunci ; Kota Manado, Ssistem Informasi Geografis , Google Map

\section{PENDAHULUAN}

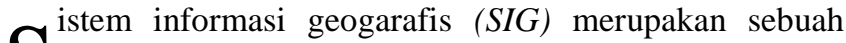
sistem yang memberikan informasi yang berkaitan dengan peta (geografis). Sistem ini dapat memetakan suatu tempat baik berupa batas wilayah, jalan, sungai, maupun kondisi geografis lainnya. Dengan adanya sistem informasi geografis diharapkan dapat memberikan suatu informasi yang lebih informatif dan fleksibel. Hal ini dikarenakan $S I G$ mampu membantu dalam hal mengatur data dari berbagai masalah untuk memahami dari sisi spasialnya. SIG saat ini digunakan dalam berbagai bidang, salah satunya pada pemerintahan.

Pada tahun 2010 semua PEMDA (Pemerintah Daerah) diharapkan memiliki Perda bangunan gedung sebagai tindak lanjut Undang-Undang Nomor 28 tahun 2002 tentang bangunan gedung dan Peraturan Pemerintah Nomor 36 tahun 2005. Hal ini merupakan ujung tombak dalam pengaturan penyelenggaraan bangunan gedung. Dengan adanya Perda itu

maka penyelenggaraan bangunan gedung nantinya akan berlangsung tertib dan tercapainya keandalan bangunan sesuai dengan fungsinya.

Di Kota Manado masih banyak penertiban bangunan yang tidak memiliki IMB yang dilakukan dengan cara memberikan teguran. Karena bangunan tersebut bisa mengganggu hubungan bermasyarakat, ketertiban masyarakat, dan lalu lintas. Oleh karena itu petugas dari Dinas Tata Kota akan turun langsung ke tiap-tiap rumah masyarakat dan akan

melakukan pengecekan IMB-nya, proses pengecekan bangunan dilakukan dengan mengecek karakteristik dan fungsionalitas bangunan tersebut pada berkas IMB yang ada, apabila tidak memiliki IMB atau memiliki IMB namun fungsionalitas dan karakteristik bangunan tidak sesuai yang terdaftar maka pemerintah akan memberikan teguran untuk merombak bangunan tersebut, jika tidak diindahkan maka pemerintah berkewenangan untuk membongkarnya.

\section{DASAR TEORI}

\section{A. Sistem Informasi Geografis (SIG)}

Sistem Informasi Geografis (SIG) merupakan komputer yang berbasis pada sistem informasi yang digunakan untuk memberikan bentuk digital dan analisa terhadap permukaan geografi bumi. Seiring dengan kemajuan dan perkembangan komputer, SIG ini telah mengalami kemajuan dan perkembangan yang sangat pesat sehingga merupakan suatu keharusan dalam perencanaan, analisis, dan pengambilan keputusan atau kebijakan. Kemajuan dan perkembangan SIG ini didorong oleh kemajuan dan perkembangan komputer, serta teknologi penginderaan jauh melalui pesawat udara dan satelit yang telah dimiliki oleh hampir sebagian besar negara maju di dunia.

SIG atau Geography Information System (GIS) memiliki pengertian yang selalu berubah sesuai dengan perkembagannya. Berikut ini pengertian SIG menurut Gistut (1994), SIG adalah sistem yang dapat mendukung pengambilan keputusan spasial dan mampu mengintegrasikan deskripsi- deskripsi lokasi dengan karakteristik-karakteristik fenomena yang ditemukan di lokasi tersebut. SIG yang lengkap mencakup metodologi dan teknologi yang diperlukan yaitu data spasial perangkat keras, perangkatlunak dan struktur organisasi.

Dari pengertian-pengertian yang dikemukakan ahli tersebut, dapat kita simpulkan bahwa pengertian SIG adalah suatu sistem informasi yang digunakan untuk memasukkan, menyimpan, memanggil kembali, mengolah, menganalisis, dan menghasilkan data berferensi geografis atau data geospasial. 


\section{B. Metodologi Waterfall}

Menurut Pressman (2010), Metodologi Waterfall merupakan salah satu model dalam perancangan piranti lunak. Model waterfall adalah sebuah contoh dari proses perencanaan, dimana semua proses kegiatan harus terlebih dahulu direncanakan dan dijadwalkan sebelum dikerjakan. Proses dari metode waterfall antara lain Communication, Planning, Modeling, Construction dan Deployment.

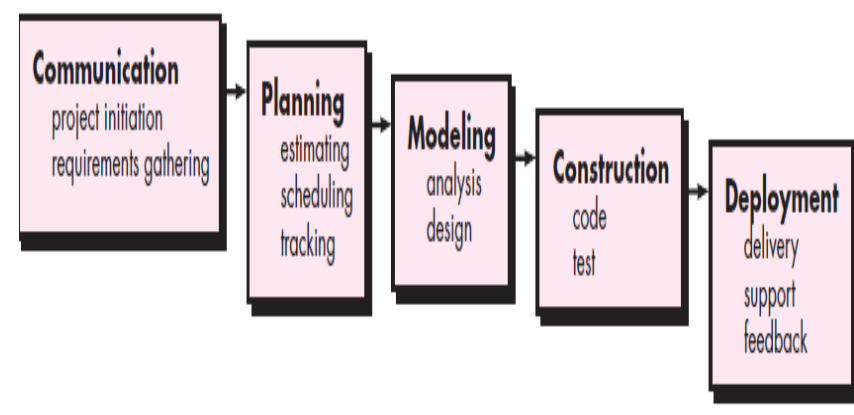

Gambar 1. Model proses waterfall

Dengan menggunakan metodologi waterfall proses akan menjadi lebih teratur, urutan proses pengerjaan menggunakan metode ini menjadi lebih teratur dari satu tahap ketahap yang selanjutnya. Dari sisi user juga lebih menguntungkan karena dapat merencanakan dan menyiapkan seluruh kebutuhan data dan proses yang akan diperlukan. Jadwal menjadi lebih menentu, jadwal setiap proses dapat ditentukan secara pasti. Sehingga dapat dilihat jelas target penyelesaian pengembangan program. Dengan adanya urutan yang pasti, dapat dilihat pula progress untuk setiap tahap secara pasti.

\section{Izin Mendirikan Bangunan (IMB)}

Izin Mendirikan Bangunan atau biasa dikenal dengan IMB adalah perizinan yang diberikan oleh Kepala Daerah kepada pemilik bangunan untuk membangun baru, mengubah, memperluas, mengurangi, dan/atau merawat bangunan sesuai dengan persyaratan administratif dan persyaratan teknis yang berlaku.

IMB merupakan salah satu produk hukum untuk mewujudkan tatanan tertentu sehingga tercipta ketertiban, keamanan, keselamatan, kenyamanan, sekaligus kepastian hukum.Kewajiban setiap orang atau badan yang akan mendirikan bangunan memiliki Izin Mendirikan Bangunan terdapat pada Pasal 5 ayat 1 Perda 7 Tahun 2009. IMB tersebut melegalkan suatu bangunan yang direncanakan sesuai dengan Tata Ruang yang telah ditentukan dan rencana kostruksi bangunan tersebut juga dapat di pertanggungjawabkan dengan maksud untuk kepentingan bersama. Sehingga jelas bahwa IMB itu penting.

Selain hal tersebut memiliki bangunan yang telah ber-IMB juga memiliki kelebihan dibandingan dengan bangunan yang tidak ber-IMB, yakni :

1. Bangunan memiliki nilai jual yang tinggi

2. Jaminan Kredit Bank

3. Peningkatan Status Tanah
4. Informasi Peruntukan dan Rencana Jalan

D. Google API

Google menyediakan berbagai API (Application Programming Interface) yang sangat berguna bagi pengembangan web maupun aplikasi desktop untuk memanfaatkan berbagai fitur yang disediakan oleh google seperti misalnya : AdSense, Search Engine, Translation maupun YouTube. API secara sederhana bisa diartikan sebagai kode program yang merupakan antarmuka atau penghubung antara aplikasi atau web yang kita buat dengan fungsi-fungsi yang dikerjakan. Misalnya dalam hal ini Google API berarti kode program (yang disederhanakan) yang dapat kita tambahkan pada aplikasi atau web kita untuk mengakses, menjalankan, memanfaatkan fungsi atau fitur yang disediakan Google. Misalnya saja kita bisa menambahkan fitur Google Maps pada website kita.

\section{METODOLOGI PENELITIAN}

\section{A. Komunikasi}

Pada tahap ini, penulis melakukan komunikasi langsung dengan pihak Dinas Tata Kota Manado. Komunikasi yang dilakukan berupa wawancara dengan Kepala Bidang. Wawancara dilakukan sebanyak satu kali, wawancara dilakukan untuk mengetahui kebutuhan perangkat lunak yang akan dibangun.

\section{B. Pemodelan}

Pada tahap ini, semua hasil analisa kebutuhan pengguna dan kebutuhan sistem didefinisikan dalam bentuk diagram UML sedangkan interface sistem dimodelkan dengan storyboard

\section{- Usecase Diagram}

Penulis menggunakan usecase diagram untuk mendefinisikan aktivitas-aktivitas pengguna sistem dan interaksi antara pengguna dengan sistem maupun interaksi antar pengguna. Usecase diagram aplikasi pemetaan bangunan berizin dapat dilihat pada Gambar 2 .

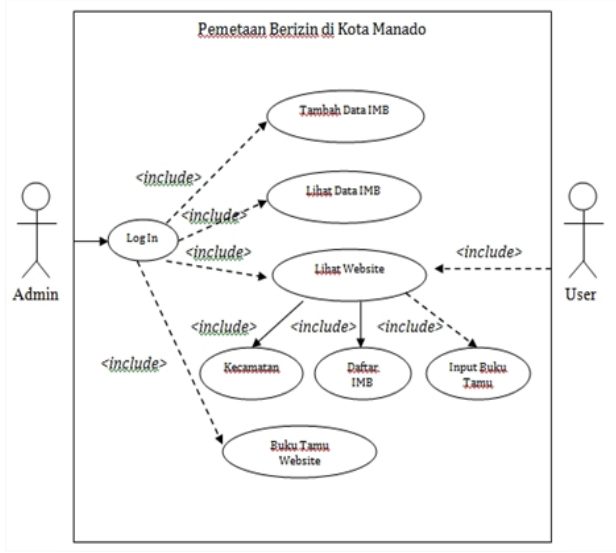

Gambar 2. Usecase Diagram 


\section{HASIL}

Pada saat selesai melakukan semua tahapan dengan metodologi yang digunakan, maka pada tahap ini akan dijelaskan hasil dari perancangan yang dilakukan berdasarkan tujuan awal yaitu membuat suatu aplikasi pemetaan bangunan berizin di Kota Manado.

\section{A. Halaman awal website}

Berikut ini adalah interface dari aplikasi pemetaan bangunan berizin di Kota Manado. Tampilan ini merupakan tampilan awal dari sistem, yang di dalamnya tersedia fitur home, kecamatan, daftar IMB, dan login. Pada tampilan home terdapat seratus balon yang diberi warna merah yang di dalamnya terdapat data IMB yang sudah memiliki izin, sedangkan pada samping kiri bawah terdapat link yang berisi titik lokasi IMB yang sudah diberi warna pada masing-masing kecamatan.

Tampilanya seperti pada gambar 3 .

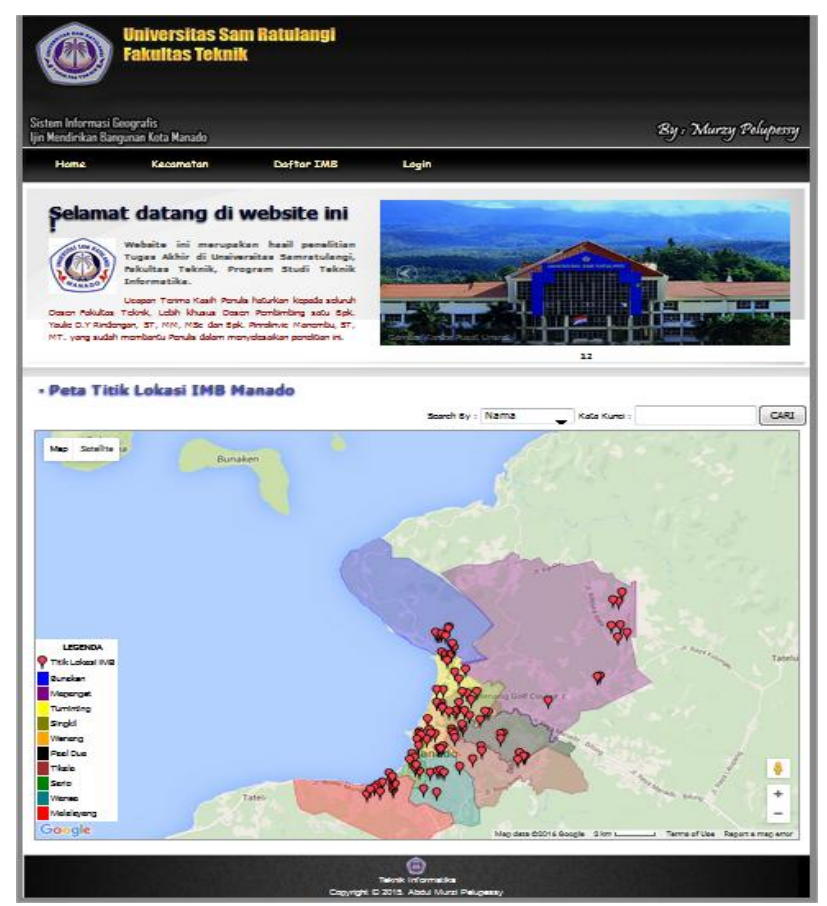

Gambar 3. Halaman awal website

\section{B. Halaman kecamatan}

Saat memilih link kecamatan, maka muncul tampilan yang berisi 10 kecamatan yang ada di kota manado, seperti kecamatan bunaken, kecamatan mapanget, kecamatan tuminting, kecamatan singkil, kecamatan wenang, kecamatan paal dua, kecamatan tikala, kecamatan sario, kecamatan wanea dan kecamatan malalayang. Tampilanya seperti pada gambar 4 .

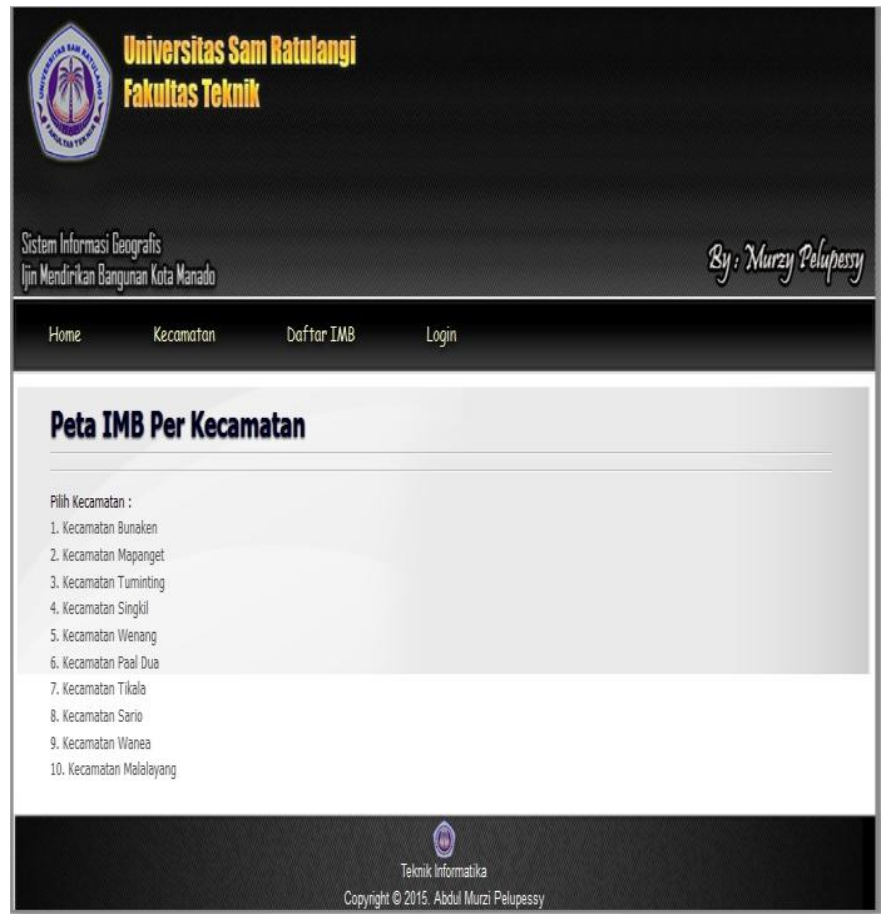

Gambar 4. Halaman kecamatan

Pada saat memilih link kecamatan pada gambar 4 . Maka selanjutnya kita memilih salah satu kecamatan yang akan kita tampilkan, contoh kecamatn paal dua maka akan muncul peta yang berisi data IMB. Yang di dalamnya berisi nama pemilik, foto, koordinat, lokasi, nomor SKRD, nomor IMB, peruntukan, dan konstruksi. Pada kecamatan paal dua data yang diambil merupakan data sampel karena dari banyaknya rumah atau bangunan yang sudah memiliki IMB saya hanya mengambil sembilan data yang berada di kecamatan paal dua. Tampilanya seperti pada gambar 5 .

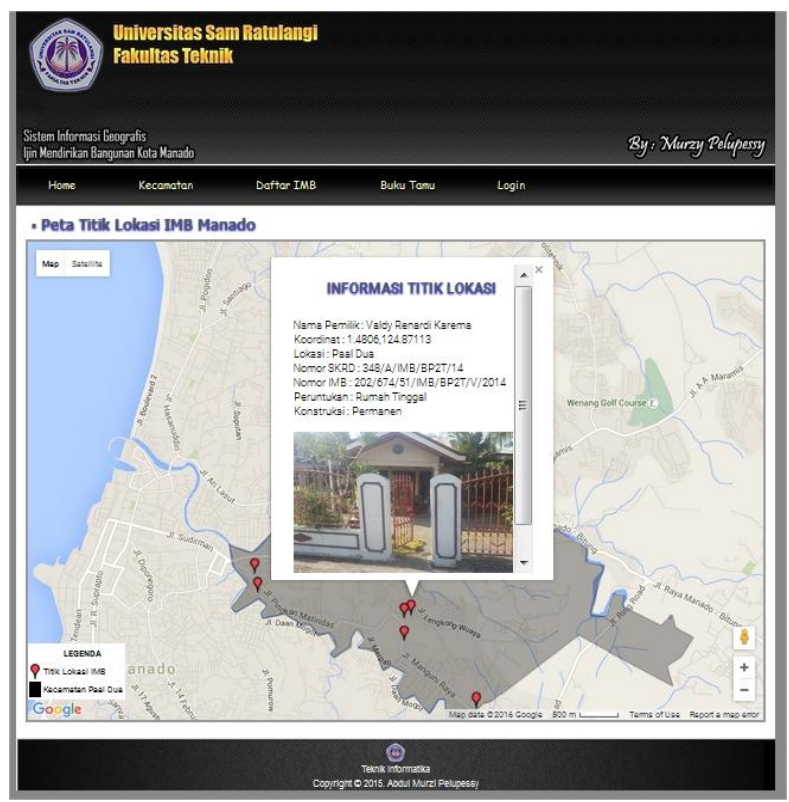

Gambar 5. Kecamatan paal dua 
Selanjutnya pada saat memilih kecamatan malalayang, maka akan muncul peta yang berisi data IMB. Yang di dalamnya berisi nama pemilik, foto, koordinat, lokasi, nomor SKRD, nomor IMB, peruntukan, dan konstruksi. Pada kecamatan malalayang data yang diambil merupakan data real karena data yang diambil merupakan data yang diberi langsung oleh dinas terkait. Tampilannya seperti pada gambar 6.

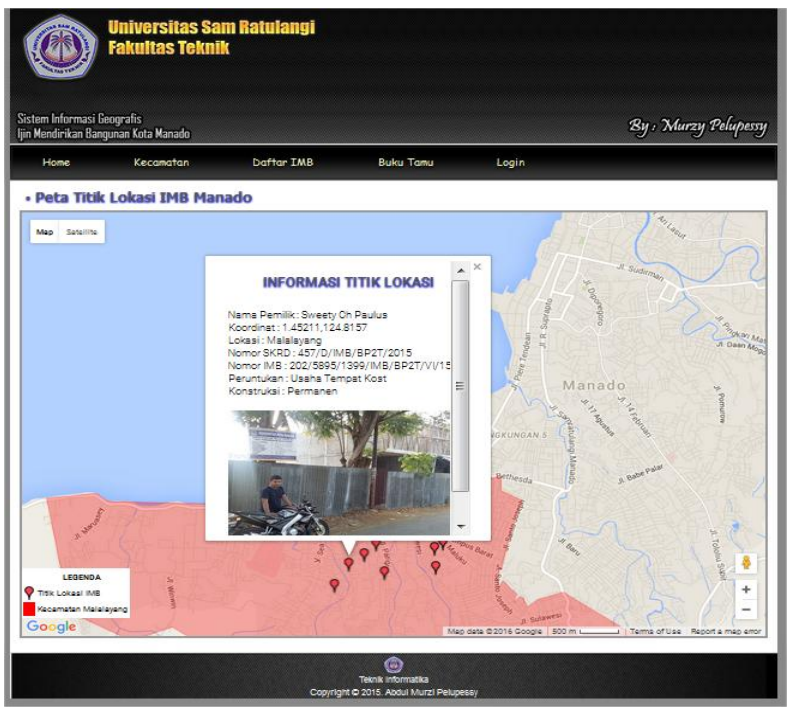

Gambar 6. Kecamatan malalayang

\section{Halaman daftar IMB}

Pada saat memilih link daftar IMB maka tampilan akan memunculkan daftar IMB yang telah terdaftar sebanyak 100 data, tampilanya berupa tabel yang berisi nama pemilik, lokasi, peruntukan, konstruksi, nomor SKRD, nomor IMB, tanggal, dan luas. tampilanya seperti pada gambar 7 .

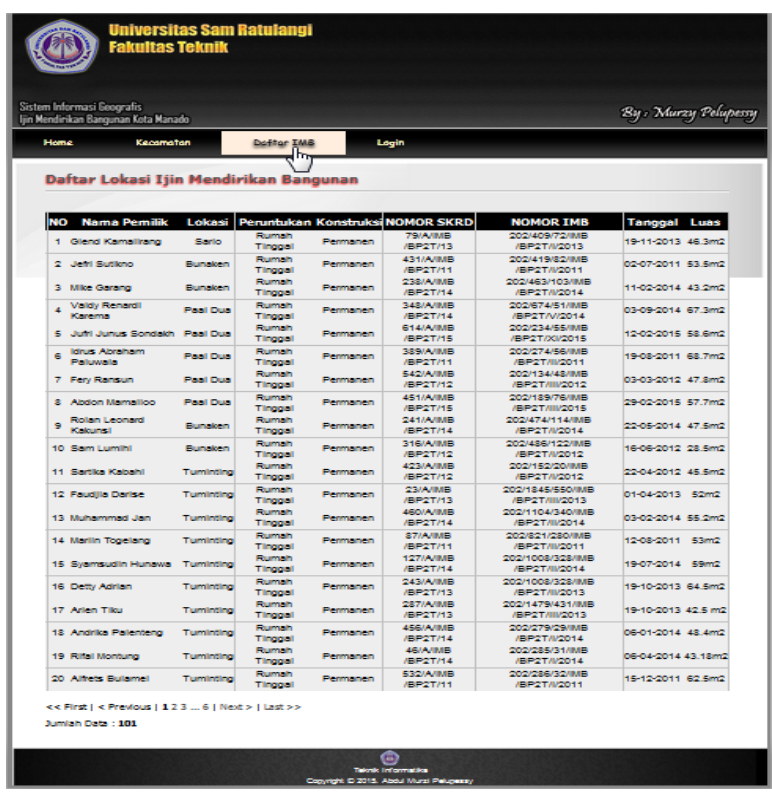

Gambar 7. Daftar IMB

\section{Halaman login}

Pada saat memilih link login, maka muncul tampilan administrator login, tampilan ini merupakan tampilan awal dari sistem, untuk menggunakan fitur-fitur yang ada pada tampilan ini, admin harus menginput username dan password setelah itu klik login agar dapat masuk ke halaman awal admin. Tampilanya seperti pada gambar 8 .

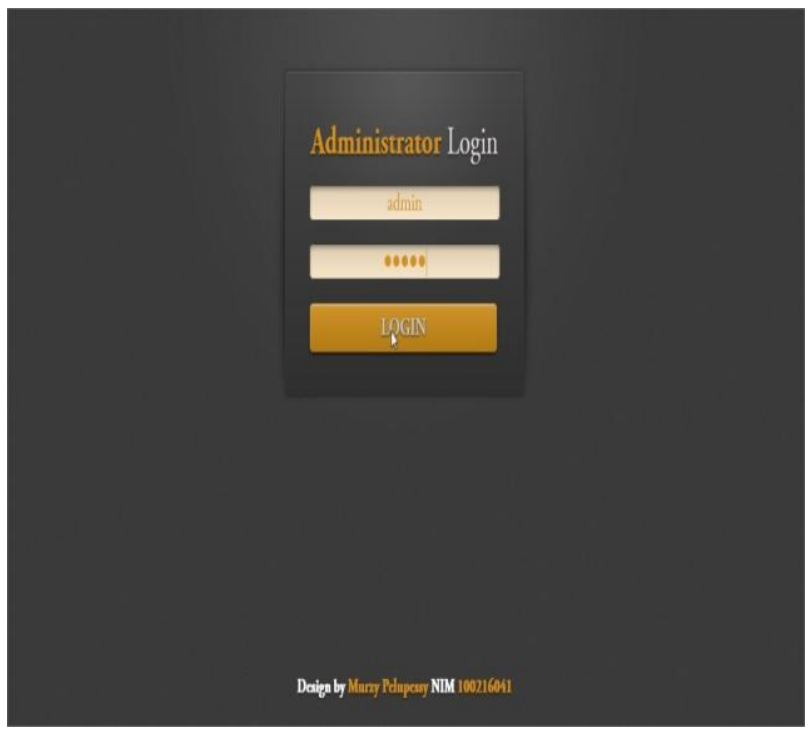

Gambar 8. Halaman login

E. Halaman utama admin

Setelah selesai login, maka muncul tampilan admin yang di dalamnya berisi folder lihat data IMB, tambah data IMB, kelola data user, lihat website dan logut. Tampilanya seperti pada gambar 9 .

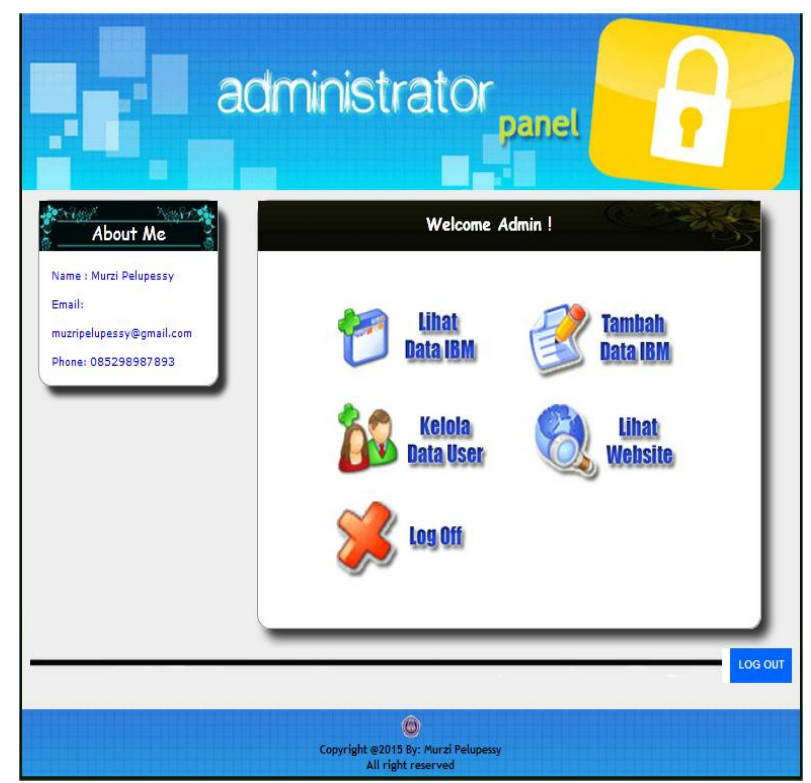

Gambar 9. Halaman utama admin 


\section{F. Data lokasi IMB}

Pada saat memilih link lihat data IMB, maka akan muncul tampilan yang berisi data lokasi izin mendirikan bangunan, yang di dalam tabel tersebut terdapat 100 data IMB dimana kita dapat mengedit data tersebut atau menghapus data yang di inginkan. Tampilanya seperti gambar 10 .

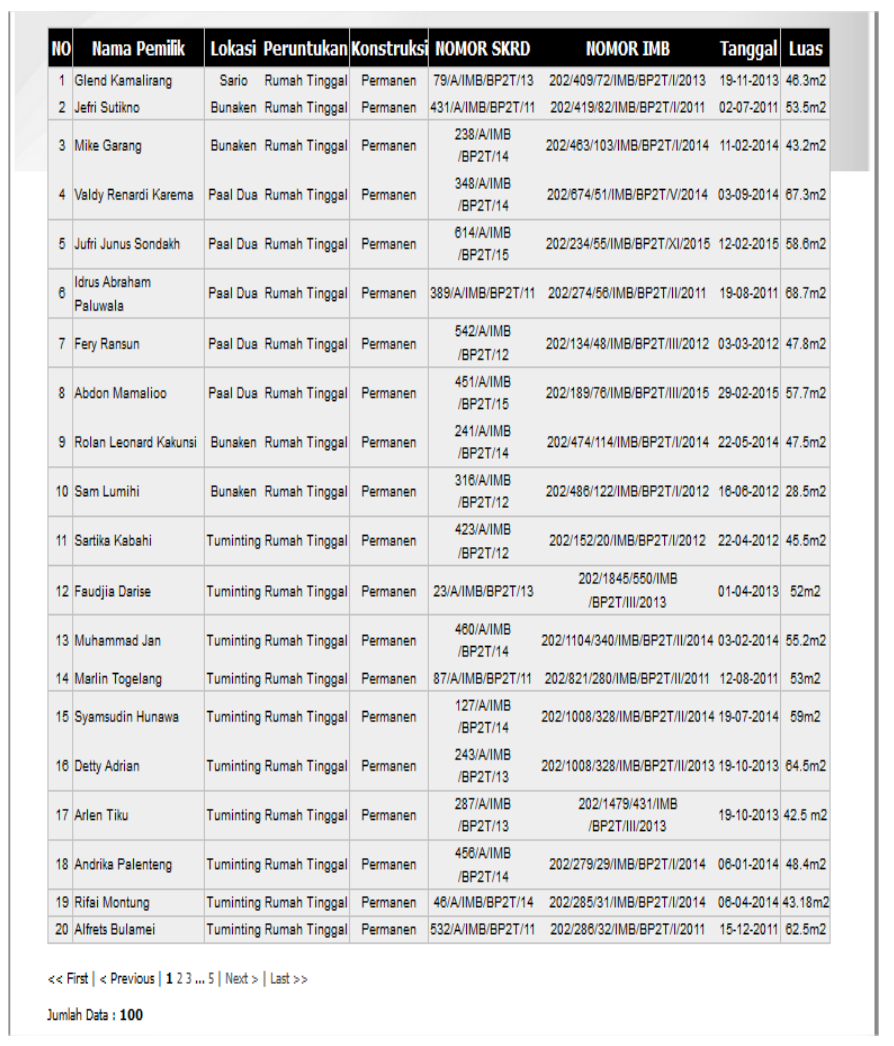

Gambar 10. Data lokasi IMB

\section{G. Input lokasi IMB}

Kemudian pada saat memilih link tambah data IMB maka tampilan akan muncul berupa input lokasi izin mendirikan bangunan, dalam tabel tersebut terdapat no, nama pemilik, lokasi, peruntukan, konstruksi, nomor SKRD, nomor IMB, tanggal, luas, koordinat bujur, koordinat lintang dan foto lokasi. Tampilan dari input lokasi izin mendirikan bangunan bisa di lihat pada gambar 11 .

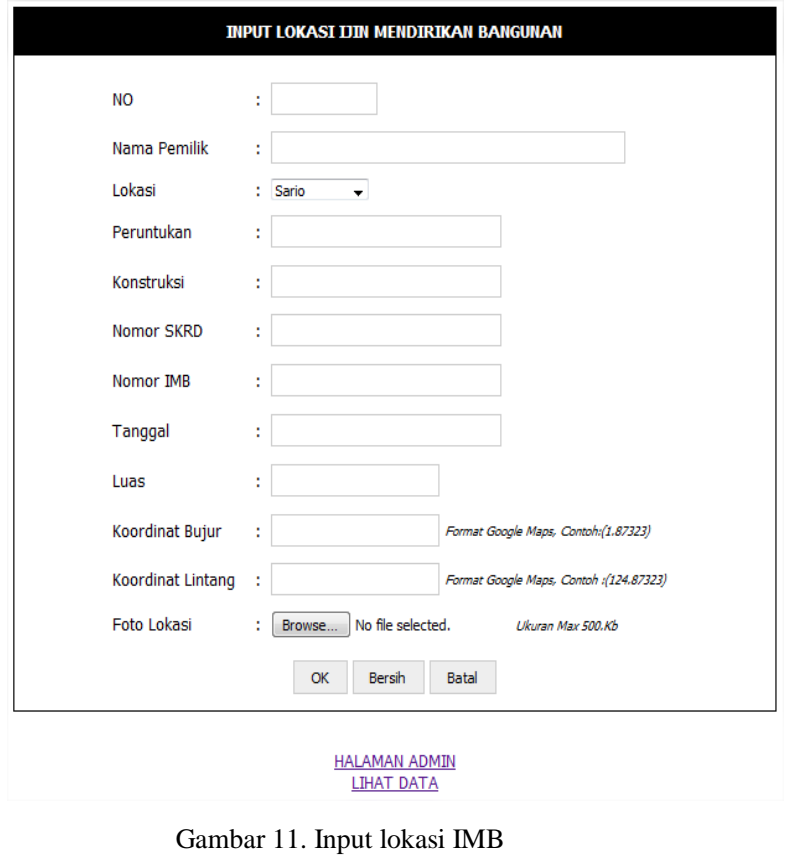

H. Input data user

Kemudian pada saat memilih link dari kelola data user makan tampilan akan muncul berupa tambah data user agar pengelolah dari aplikasi ini bisa lebih dari satu admin. Tampilannya seperti pada gambar 12 .

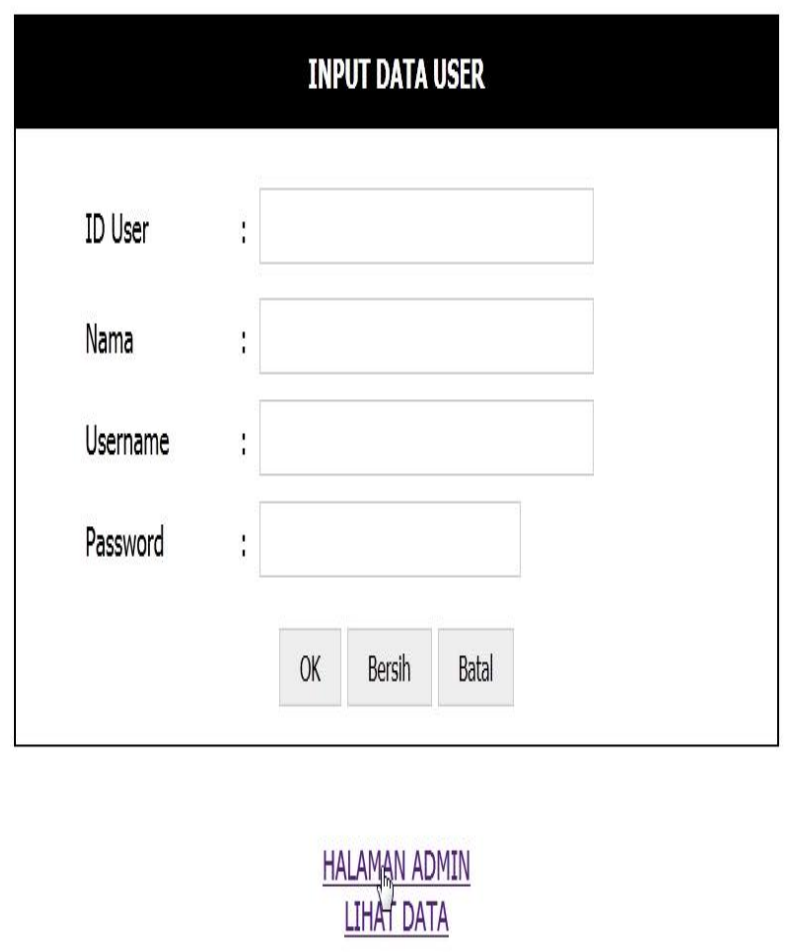

Gambar 12. Input data user 


\section{PENUTUP}

A. Kesimpulan

Berdasarkan proses dan tahap-tahap yang telah dilakukan dalam penelitian ini, maka dapat di tarik kesimpulan bahwa :

- Aplikasi pemetaan bangunan berizin di Kota Manado, yang telah dihasilkan pada perancangan ini dapat mengetahui letak bangunan yang sudah memiliki IMB berupa nama pemilik, lokasi, peruntukan, nomor SKRD, nomor IMB, tanggal, dan luas.

- Untuk merancang aplikasi pemetaan banggunan berizin di Kota Manado, diharapkan dapat memudahkan pihak Dinas Tata Kota manado, untuk mengetahui bangunan mana saja yang sudah terdaftar IMB.

- Pembuatan aplikasi pemetaan bangunan berizin di Kota Manado, telah dilakukan dengan cara pengumpulan data baik berupa data real maupun data sample agar memudahkan dalam mengerjakan aplikasi yang di buat.

B. Saran

Untuk pengembangan aplikasi ini, akan lebih baiknya jika aplikasi bisa dapat di lihat secara langsung di situs resmi Tata Kota Manado, agar dapat memudahkan masyarakat Kota Manado untuk melihat lokasi yang di bolehkan untuk adanya IMB

\section{DAFTAR PUSTAKA}

[1] A.S, Rossa dan M. Shalahuddin. (2013). Rekayasa Perangkat Lunak Terstruktur dan Berorientasi Objek. Bandung : Penerbit Informatika.

[2] Achmad Solichin. 2009. Pemrograman Web Dengan PHP dan MySQL. Jakarta

[3] Betha, Sidik, 2005, MySQL untuk Pengguna Administrator dan Pengembangan Aplikasi Web, Informatika, Bandung.

[4] Fathansyah, Ir. 2002. Basis Data, Informatika.

[5] Jogiyanto, H.M. 2005. Analisa dan Desain Sistem Informasi : Pendekatan Terstruktur Teori dan Praktik Aplikasi Bisnis, Andi, Yogyakarta.

[6] Kendall. 2008. Analisis \& Perancangan Aplikasi. Jakarta : Index

[7] Muhammad, Hadi, 2007, Sistem Informasi Geografis Berbasis Web Potensi Bisnis di Kota Bandung, Jurnal Jurusan Teknik Informatika, Universitas Komputer Bandung, Bandung.

[8] Prahasta, Eddy. 2003. Sistem Informasi Geografis : Konsep-konsep Aplikasi Informasi Geografis. Informatika, Bandung.

[9] Roger S. Pressman, Ph. D. 2012. Rekayasa Perangkat Lunak. Yogyakarta : Andi..

[10] Syahidin, Yuda. 2006. Modul Kuliah Pemrograman Web I. PIKSI Ganesha. Bandung. Nurpilihan Bafdal, Kharistya Amaru, Boy Macklin Pareira P. 2001. Buku Ajar Sistem Informasi Geografis, Edisi 1. Bandung.

[11] Tim Peneliti. 2010. Manual Penggunaan Software Open Source Quantum GIS untuk Membangun Aplikasi Sistem Informasi Geografis.
Jakarta: Pusat Pengembangan Pemanfaatan dan Teknologi Penginderaan Jauh - LAPAN

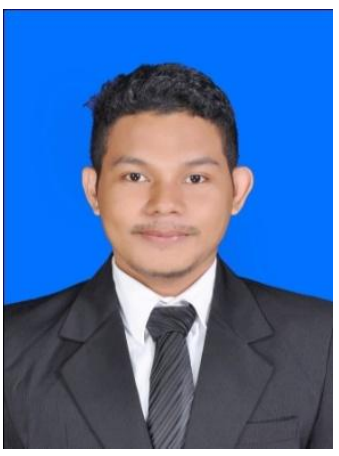

Penulis bernama lengkap Abdul Murzi Pelupessy, anak ketiga dari tiga orang bersaudara. Lahir di Ternate, pada tanggal 03 Februari 1992. Dengan alamat tempat tinggal sekarang Malalayang I, J1. Mogandi 10. Sekolah pertama tempat belajar adalah Taman Kanak-kanak Aisia, Ternate. Selanjutnta, melanjutkan ke SD Negeri Islamiah 6 Kota Ternate. Selanjutnya, melanjutkan ke SMP Negeri 2 Kota Ternate. Dan menyelesaikan sekolah tingkat atas di SMA Negeri 5 Kota Ternate.

Pada tahun 2010, Penulis melanjutkan studi di Fakultas Teknik, Jurusan Elektro, Program Studi Informatika Universitas Sam Ratulangi Manado. Selama kuliah, Penulis tergabung dalam organisasi Himpunan Mahasiswa Elektro (HME) dan Badan Tazkir Fakultas Teknik UNSRAT. 